FACTA UNIVERSITATIS

Series:Mechanical Engineering Vol. 14, Nº 2, 2016, pp. 169 - 177

Original scientific paper

\title{
BROWNIAN HEAT TRANSFER ENHANCEMENT IN THE TURBULENT REGIME
}

\author{
UDC 536.2:532.5
}

\author{
Suresh Chandrasekhar, Vaarin Majumdar Sharma \\ Department of Mechanical-Mechatronics Engineering, LNM Institute of Information \\ Technology, India
}

\begin{abstract}
The paper presents convection heat transfer of a turbulent flow Al2O3/water nanofluid in a circular duct. The duct is a under constant and uniform heat flux. The paper computationally investigates the system's thermal behavior in a wide range of Reynolds number and also volume concentration up to 6\%. To obtain the nanofluid thermophysical properties, the Hamilton-Crosser model along with the Brownian motion effect are utilized. Then the thermal performance of the system with the nanofluid is compared to the conventional systems which use water as the working fluid. The results indicate that the use of nanofluid of $6 \%$ improves the heat transfer rate up to $36.8 \%$ with respect to pure water. Therefore, using the Al2O3/water nanofluid instead of water can be a great choice when better heat transfer is needed.
\end{abstract}

Key Words: Nanofluid, Forced Convection, Heat Transfer Enhancement, Turbulence Flow

\section{INTRODUCTION}

In the past years, many different techniques were utilized to improve the heat transfer rate in order to get higher thermal efficiencies. Thus adding solid particles to a base fluid was suggested by Maxwell [1, 2]. However, large particles cause many serious problems. Choi [3] suggested the use of nano-sized particles.

After that, the researcher tried to understand the effects of those nanoparticles on heat transfer efficiency of the system. In recent years, some numerical studies have been done on the forced or free convection of laminar flows of the nanofluids [4-7]. The results reveal that using nanofluid can enhance heat transfer performance of nanofluid compared to pure water. Also, some studies have focused on the turbulent flow of nanofluids. Heat transfer investigation of nanofluids flow in the turbulent regimes was numerically

Received April 5, 2016 / Accepted June 15, 2016

Corresponding author: Suresh Chandrasekhar

Department of Mechanical-Mechatronics Engineering, The LNM Institute of Information Technology, India

E-mail:sur.chandrasekhar@gmail.com 
performed. Manca et al. [8] numerically investigated the turbulent forced convection with nanofluids in $2 \mathrm{D}$ channel. They have used a single-phase approach and observed that the heat transfer enhancement increases with the particle volume concentration. Besides, Roy et al. [9] compared the performance of different nanofluids inside a typical radial flow cooling device. They reported that the heat transfer increases with volume concentration and Reynolds number. Bianco et al. [10] also numerically studied water$\mathrm{Al}_{2} \mathrm{O}_{3}$ nanofluids turbulent convection heat transfer inside a circular tube. They reported that the heat transfer enhancement increases with the particle volume concentration and Reynolds number; their results were in good agreement with those of other studies. Moreover, the heat transfer enhancement of $\mathrm{TiO} 2$ and water in a circular tube were investigated by Demir et al. [11]. A single-phase model having two-dimensional equations was employed for this simulation and they reported a noticeable jump in the heat transfer rate.

In this study, a turbulent flow of $\mathrm{Al}_{2} \mathrm{O}_{3}$ /water nanofluid passes through a tube which is under constant heat flux. To capture the effects of the temperature on the thermophysical properties of the nanofluid, the properties are considered temperature dependent. Also, the effect of the Brownian motion of nanoparticles is taken into account. To investigate the thermal performance of the system by using this new working fluid, the Nusselt number and the convective heat transfer coefficient are presented.

\section{MATHEMATICAL MODELING}

The geometry consists of a tube with diameter (D) of $0.01 \mathrm{~m}$ and length of $\mathrm{L}=1 \mathrm{~m}$. The $\mathrm{Al} 2 \mathrm{O} 3 /$ water nanofluid passes through this tube and a fixed heat flux is subjected to the tube wall. Volume concentration of nanoparticles ( $\phi$ ) equals $0 \%$ (base fluid), $1 \%, 2 \%, 4 \%$ and $6 \%$.

\subsection{Fluid properties}

In this study, the thermophysical properties of nanofluid are calculated based on temperature dependent models in order to capture the effects of temperature on the properties.

The effective properties of the $\mathrm{Al}_{2} \mathrm{O}_{3}$ /water nanofluid are defined as follows:

$$
\rho_{n f}=\phi_{p} \rho_{p}+\left(1-\phi_{p}\right) \rho_{b f}
$$

where $\phi_{p}$ is the volume concentration of nanoparticles, while $\rho_{p}, \rho_{b f}, \rho_{n f}$ are the density of particles, the density of the base fluid that is water and the density of nanofluid, respectively.

Eq. (1) was originally introduced in [12] for determining the density and then widely employed in literature $[4,6,10,13]$.

For defining the heat capacity, the following equation is used as in many other studies such as $[4,6,5,8,10]$ :

$$
C_{n f}=\frac{\phi_{p} \rho_{p} C_{p}+\left(1-\phi_{p}\right) \rho_{b f} C_{b f}}{\rho_{n f}}
$$

In order to get the nanofluid thermal conductivity, many referential studies have used the Hamilton and Crosser model [14]:

$$
\frac{k_{n f}}{k_{b f}}=\frac{k_{p}+(n-1) k_{b f}-(n-1) \phi_{p}\left(k_{b f}-k_{p}\right)}{k_{p}+(n-1) k_{b f}+\phi_{p}\left(k_{b f}-k_{p}\right)}
$$


In this model, $n$ is an empirical shape factor which accounts for the effect of shape of particles; it can vary from 0.5 to 6.0 . For spherical nanoparticles $n$ equals 3 . So this case of the Hamilton and Crosser model $(n=3)$ is:

$$
\frac{k_{n f}}{k_{b f}}=\frac{k_{p}+2 k_{b f}-2 \phi_{p}\left(k_{b f}-k_{p}\right)}{k_{p}+2 k_{b f}+\phi_{p}\left(k_{b f}-k_{p}\right)}
$$

However, this equation only takes into account the nanoparticles shape and volume concentration; it cannot take into account the Brownian motion of nanoparticles inside the fluid. However, in this study, we consider the effect of the Brownian motion of nanoparticles. For this purpose, we need to modify the Hamilton-Crosser model by using the formals proposed by Koo and Kleinstreuer [15]:

$$
k_{\text {Brownian }}=5 \times 10^{4} \beta \phi \rho_{b f} C_{b f} \sqrt{\frac{\kappa_{B} T}{\rho_{p} d_{p}}}
$$

where:

$$
\beta=0.0017(100 \phi)^{-0.0841}, \phi \geq 1 \%
$$

Besides, the viscosity of nanofluid is calculated based on the Einstein model:

$$
\mu_{n f}=\mu_{b f}(1+2.5 \phi)
$$

\subsection{Governing equations}

To capture the turbulence effect, standard $\kappa-\varepsilon$ model is adapted. This $\kappa-\varepsilon$ model has two additional equations for turbulent kinetic energy $\kappa$ and the rate of dissipation $\varepsilon$ in the following form:

$$
\begin{gathered}
\nabla \cdot(\rho \vec{V} \kappa)=\nabla \cdot\left(\left(\mu+\frac{\mu_{t}}{\sigma_{k}}\right) \nabla \kappa\right)+P_{k}-\rho \varepsilon \\
\nabla \cdot(\rho \vec{V} \varepsilon)=\nabla \cdot\left(\left(\mu+\frac{\mu_{t}}{\sigma_{\varepsilon}}\right) \nabla \varepsilon\right)+\frac{\varepsilon}{\kappa} C_{1 \varepsilon} P_{k}-\frac{\varepsilon^{2}}{\kappa} C_{2 \varepsilon} \rho
\end{gathered}
$$

where the eddy viscosity is calculated by:

$$
\begin{gathered}
\mu_{t}=\rho C_{\mu} \frac{\kappa^{2}}{\varepsilon} \\
C_{1 \varepsilon}=1.44, C_{2 \varepsilon}=1.92, C_{\mu}=0.09, \sigma_{k}=1, \sigma_{\varepsilon}=1.3
\end{gathered}
$$

Besides, the governing equations for solving the problem are continuity, momentum and energy equations as follows:

$$
\begin{gathered}
\nabla \cdot(\rho \vec{V})=0 \\
\nabla \cdot(\rho \vec{V} \vec{V})=-\nabla P+\nabla \cdot\left(\mu \nabla \vec{V}-\rho \overline{v^{\prime} v^{\prime}}\right) \\
\nabla \cdot\left(\rho C_{p} T \vec{V}\right)=\nabla \cdot\left(k \nabla T-\rho C_{p} \overline{t^{\prime} v^{\prime}}\right)
\end{gathered}
$$




\subsection{Numerical method}

In order to discretize the governing equations, a control volume approach is employed by using ANSYS Fluent. Also, a collocated grid system is used so that the grid near the wall is smaller in order to capture turbulence effects near the wall. Several unstructured grids have been created to assure consistency and accuracy of the numerical results. A grid independency test is done by comparison of the results obtained from employing different grids in terms of the local Nusselt number and the relevant errors showed that the $700 \times 150$ non-uniform grid is good enough to ensure the independency of numerical results from the grid system. This grid consists of 150 nodes in radial $(r)$ and 700 nodes in longitudinal direction $(x)$.

The boundary conditions consist of an uniform inlet temperature, $T_{i n}=293 \mathrm{~K}$ also a uniform entrance velocity $u_{\text {in }}$ which can be calculated from Reynolds number based on the following equation, and the non-slip condition is set for the velocities at the walls.

$$
u_{i n}=\frac{\mu \mathrm{Re}}{\rho D}
$$

Further, the constant intensity turbulence of $1 \%$ is imposed. Also, a uniform heat flux is applied at the pipe wall. Moreover, both turbulent kinetic energy and dissipation of turbulent kinetic energy are equal to zero. At the channel exit, the fully developed assumption is employed which means that all the axial derivatives are zero.

\section{RESULTS AND DISCUSSION}

In order to validate the numerical method, the current numerical Nusselt number of the pure water is compared to some models represented in the following equations presented in [13] versus Reynolds numbers in Fig. 1. This figure shows that there is a good agreement between the numerical results obtained from the current study and other models and studies.

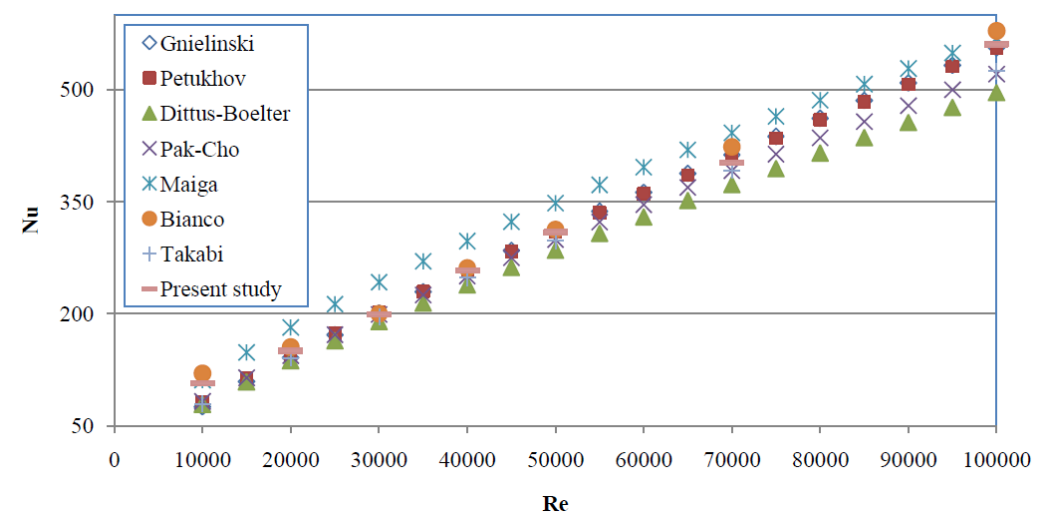

Fig.1 Comparison of the present numerical results with other works 


$$
N u=\frac{\left(\frac{f}{2}\right)\left(\operatorname{Re}-10^{3}\right) \operatorname{Pr}}{1+12.7\left(\frac{f}{2}\right)^{1 / 2}\left(\operatorname{Pr}^{2 / 3}-1\right)}\left(\frac{f}{2}\right)
$$

Dittus-Boelter:

$$
N u=0.024 \operatorname{Re}^{0.8} \operatorname{Pr}^{0.4} \quad \text { Heating }
$$

Petukhov:

$$
N u=\frac{\operatorname{Re} \operatorname{Pr}\left(\frac{f}{8}\right)}{1.07+12.7\left(\operatorname{Pr}^{2 / 3}-1\right) \sqrt{\frac{f}{8}}}
$$

Fig. 2 shows the local heat transfer coefficient of water and nanofluids 1, 2, 4 and 6\% for constant Reynolds number of 20000. This figure shows that by replacing the $\mathrm{Al} 2 \mathrm{O} 3 /$ water nanofluid by pure water, the heat transfer coefficient increases. Also, by increasing the volume concentration of the dispersed nanoparticles in the base fluid, the heat transfer convective coefficient will increase as well. This enhancement in the heat transfer coefficient is because of enhancing the properties of the nanofluid due to adding some solid nano particles in the base fluid.

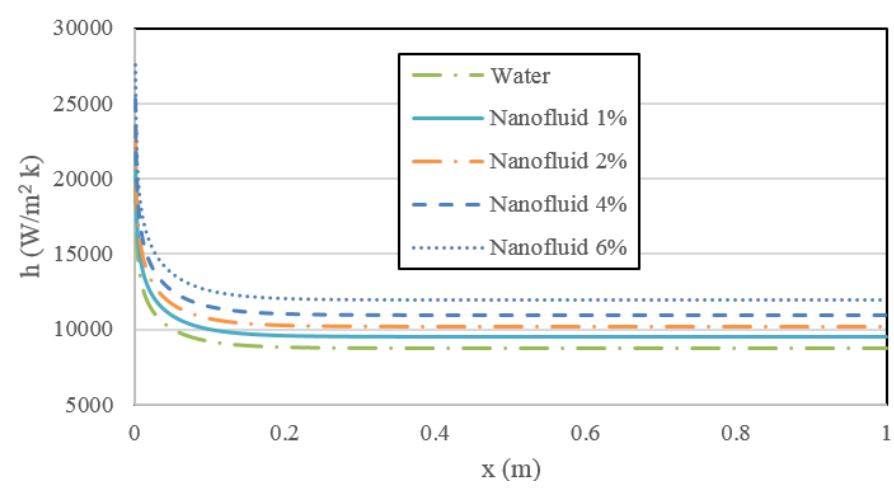

Fig. 2 Local convective heat transfer coefficient of all working fluids

As mentioned before, some studies have already explored the heat transfer performance of $\mathrm{Al}_{2} \mathrm{O}_{3}$ /water nanofluid. Therefore, in Fig. 3, comparison was made between the present study and the previous studies for the working fluid of $\mathrm{Al}_{2} \mathrm{O}_{3} /$ water nanofluid $1.0 \%$. This comparison shows that the Maiga model defined by Eq. (19) overestimates the present numerical study results.

$$
N u=0.085 \operatorname{Re}^{0.71} \operatorname{Pr}^{0.35}
$$

However, our results have a better agreement with the model developed by Pak and Cho in the following equation:

$$
N u=0.021 \operatorname{Re}^{0.8} \operatorname{Pr}^{0.5}
$$

The reason for this difference is because Maiga et al. [16] have used a correlation on the experimental data by Wang et al. [17] to define the thermophysical properties of 
$\mathrm{Al}_{2} \mathrm{O}_{3}$-water nanofluid. But those properties are noticeably different from those that Pak and Cho [12] have used in their work; the reason for this is in different nanoparticles sizes in these two studies. Besides, our results agree well with those of Bianco et al [10] and Takabi and Shokouhmand [13] since both the studies use a numerical simulation which is just like the method we use in this work.

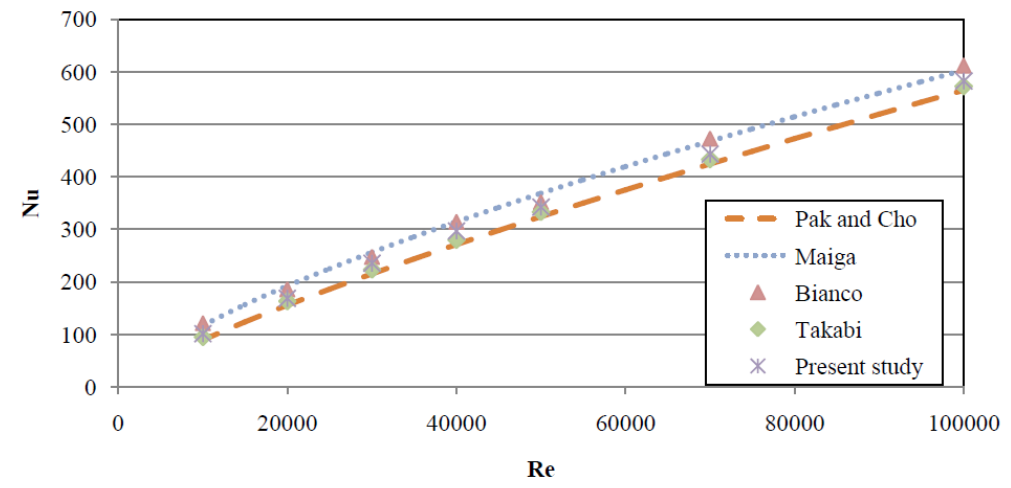

Fig. 3 Comparing $\mathrm{Nu}$ of the present study with other works

Fig. 4 shows the Nusselt number of pure water and nanofluids 1 and $2 \%$ as a function of Reynolds number. This figure shows that when we use nanofluid instead of pure water as the working fluid, we can get a higher Nusselt number. Also, when we use higher volume concentrations of nanoparticles in the nanofluid, we will obtain a higher Nusselt number. Thus we can get higher thermal performance. Therefore, from this figure, it can be concluded that we can use nanofluid in a wide range of industrial applications, especially when we need higher thermal performance. For instance, nanofluid is a good choice to use in underwater pipelines [18], or in biomechanics [19], or where we need higher thermal rejection capacity [20,21] since we can improve thermophysical properties such as higher capacity by adding nano-sized solid particles. To be more specific, once nanoparticles are added to the base fluid, the mixture has a higher thermal capacity so that it can absorb shocks and external vibrations. In other words, the nanoparticles in a flow hit the wall and absorb some energy from the wall. So they can decrease extra energy resulting from vibration or thermal shocks on the wall. Besides, nanoparticles will

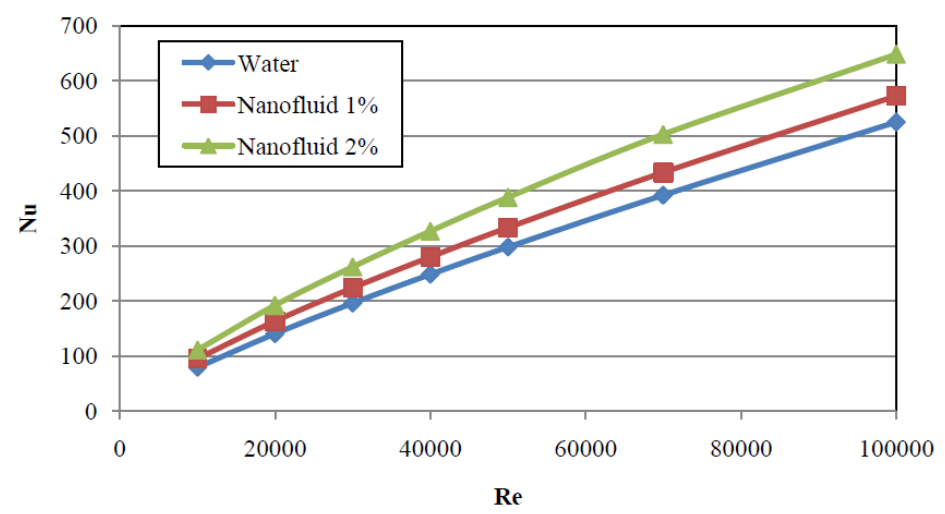

Fig. 4 Nusselt number of pure water, nanofluid $1 \%$ and $2 \%$ as a function of $\operatorname{Re}$ 
cause better thermal properties of the mixture. So, as can be seen in this figure, the slope for nanofluid $2 \%$ is steeper than for nanofluid $1 \%$ and water. Therefore, it means the nanofluid $2 \%$ has a better thermal performance than water or nanofluid $1 \%$.

In order to understand the effect of using nanofluid instead of water quantitatively, we use the average convective heat transfer coefficient ratio as the following equation which has already been used by [13] in a similar work.

$$
\bar{h}_{r}=\frac{\bar{h}_{n f}}{\bar{h}_{b f}}
$$

where $\bar{h}_{b f}$ and $\bar{h}_{n f}$ are average convective heat transfer coefficients of the base fluid which is pure water and the nanofluid which is $\mathrm{Al}_{2} \mathrm{O}_{3}$ /water nanofluid. Table 1 shows the average convective heat transfer coefficient ratio of $\mathrm{Al}_{2} \mathrm{O}_{3}$ /water nanofluid with different volume concentrations. As can be seen, all the values are greater than 1. It means that using nanofluid will increase the convective heat transfer coefficient that is good for us. Also, the concentration for $\mathrm{Al}_{2} \mathrm{O}_{3}$ /water nanofluid $1 \%$ is 1.091 , while this value for nanofluid of $6 \%$ is 1.368 . Therefore, it shows that by adding five more percent of the volume concentration, $25.4 \%$ enhancement in the average convective heat transfer coefficient is achieved.

Table 1 The average convective heat transfer coefficient ratio of nanofluid

\begin{tabular}{lcccc}
\hline Nanofluid & $\varphi=1.0 \%$ & $\varphi=2.0 \%$ & $\varphi=4 \%$ & $\varphi=6.0 \%$ \\
\hline $\bar{h}_{r}$ & 1.091 & 1.166 & 1.255 & 1.368 \\
\hline
\end{tabular}

Fig. 5 shows wall temperature and bulk temperature of water, nanofluid 1 and $2 \%$. As can be seen, when we use nanofluid, the wall temperature decreases which is favorable. This phenomenon can be used in the laser eye surgery where the laser irradiation is so high that it could damage the cornea tissues. But the use of nanofluid could decrease the temperature on the cornea surface [22].

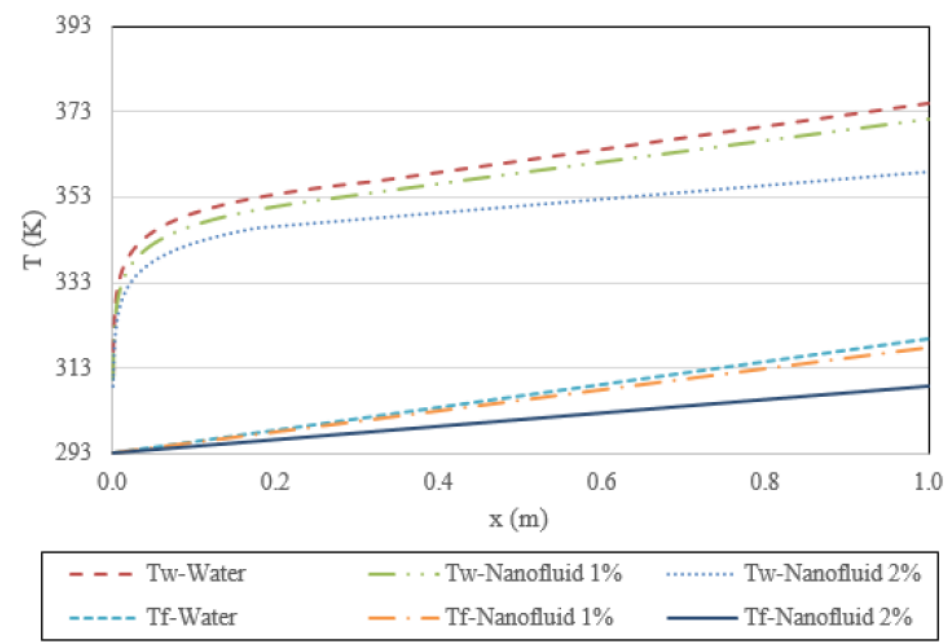

Fig. 5 Wall temperature and bulk temperature profile of water and nanofluid and $1.0 \%$ 
This behavior is also reported by Takabi and Shokouhmand [13] and Bianco et al [10]. The decrease in the nanofluid wall temperature is caused by the fact that the nanoparticles in the flow hit the wall and absorb the thermal energy of the wall, as discussed earlier. Therefore, the wall temperature of nanofluid compared to water decreases. Also, the nanoparticles can enhance the fluid's thermophysical properties. So nanofluid has a higher thermal capacity to absorb thermal energy. Furthermore, we can see that after the entrance region of the pipe, the wall temperature and the bulk temperature are getting parallel. It means the flow is fully developed in terms of heat transfer in that region which is in agreement with [23].

\section{CONCLUSIONS}

In many industrial applications, we need higher thermal performance for different equipments. Thus we can use a better working fluid such as nanofluids. Nanofluids are mixtures of some nanoparticles into a base fluid. In this study, the effect of nanofluid with different volume concentration in a circular tube under constant heat flux in a wide range of turbulent flow with the Reynolds number between 10000 to 100000 is investigated. That is why a computational approach is used based on finite volume method. The thermophysical properties of the nanofluid are obtained by using the Hamilton-Crosser model along with the Brownian motion effect. Also for the turbulence effects, standard $\kappa-\varepsilon$ model is used. The results reveal that the numerical current results are in a better agreement with other numerical studies by Bianco et al [10] and Takabi and Shokouhmand [13] than the model developed by Maiga and Pak-Cho. Also, using the nanofluid 6\% can enhance the convective heat transfer coefficient up to $36.8 \%$ compared to the base fluid, while the nanofluid of $1 \%$ has an improvement of $16.6 \%$. Therefore, using the higher volume concentrations for nanofluid can enhance the thermal performance more [24]. Besides, using the nanofluid can decrease the wall temperature which is a positive effect in the analysis.

\section{REFERENCES}

1. Maxwell, J.C., 1873, Electricity and Magnetism, Clarendon Press, Oxford.

2. Maxwell, J.C., 1881, A Treastise on Electricity and Magnetism, Second edition, Clarendon, Oxford University Press, Cambridge.

3. Choi, U.S.S., 1995, Enhancing thermal conductivity of fluids with nanoparticles, Developments and Application of Non-Newtonian Flows, ASME, 66, pp. 99-105.

4. Takabi, B., Salehi, S., 2014, Augmentation of the Heat Transfer Performance of a Sinusoidal Corrugated Enclosure by Employing Hybrid Nanofluid, Advances in Mechanical Engineering, 6, doi:10.1155/ 2014/147059.

5. Bianco, V., Chiacchio, F., Manca, O., Nardini, S., 2009, Numerical investigation of nanofluids forced convection in circular tubes, Applied Thermal Engineering, 29, pp. 3632-3642.

6. Zhu, X. W., Fu, Y. H., Zhao, J. Q., Zhu, L., 2016, Three-dimensional numerical study of the laminarflow and heat transfer in a wavy-finned heat sinkfilled with Al2O3/ethylene glycol-water nanofluid, Numerical Heat Transfer, Part A, 69(2), pp. 195-208.

7. Rea, U., McKrell, T., Hu, L., Buongiorno, J., 2009, Laminar convective heat transfer and viscous pressure loss of alumina-water and zirconia water nanofluids, International Journal of Heat and Mass Transfer, 52, pp. 2042-2048.

8. Manca, O., Nardini, S., Ricci, D., 2012, A numerical study of nanofluid forced convection in ribbed channels. Applied Thermal Engineering, 37, pp. 280-292. 
9. Roy,G., Gherasim, I., Nadeau, F., Poitras, G., Nguyen, C.T., 2012, Heat transfer performance and hydrodynamic behavior of turbulent nanofluid radial flows, International Journal of Thermal Sciences, 58, pp. $120-129$.

10. Bianco, V., Manca, O., Nardini, S., 2011, Numerical investigation on nanofluids turbulent convection heat transfer inside a circular tube, International Journal of Thermal Sciences, 50, pp. 341-349.

11. Demir, H., Dalkilic, A.S., Kürekci, N.A., Duangthongsuk, W., Wongwises, S., 2011, Numerical investigation on the single phase forced convection heat transfer characteristics of $\mathrm{TiO}_{2}$ nanofluids in a double-tube counter flow heat exchanger, International Communications in Heat and Mass Transfer, 38, pp. 218-228.

12. Pak, B.C., Cho, Y.I., 1998, Hydrodynamic and heat transfer study of dispersed fluids with submicron metallic oxide particles, Experimental Heat Transfer, 11, pp. 151-170.

13. Takabi, B., Shokouhmand, H., 2015, Effects of Al2O3-Cu/water hybrid nanofluid on heat transfer and flow characteristics in turbulent regime, International Journal of Modern Physics C, 26(4), 1550047.

14. Hamilton, R.L., Crosser, O.K., 1962, Thermal conductivity of heterogeneous two component system, Industrial \& Engineering Chemistry Fundamentals, 1, pp. 187-191.

15. Koo, J., Kleinstreuer, C., 2004, A new thermal conductivity model for nanofluids, Journal of Nanoparticle Research, 6, pp.577-588.

16. Maiga, S.E.B., Cong Tam, N., Galanis, N., Roy, G., Mare, T., 2006, Heat transfer enhancment in turbulent tube flow using $\mathrm{Al}_{2} \mathrm{O}_{3}$ nanoparticle suspention, International Journal of Numerical Methods for Heat \& Fluid Flow, 16, pp. 275-292.

17. Wang, X., Xu, X., Choi, S.U.S., 1999, Thermal conductivity of nanoparticles-fluid mixture, Journal of Thermophysics and Heat Transfer, 13(4), pp. 474-480.

18. Mirsayar, M.M., Takabi,B., 2016, Fracture of underwater notched structures, Engineering Solid Mechanics, 4 , pp. 43-52.

19. Gudarzi, M., Zamanian, H., Oveisi, A., 2013, A steady flow analysis of blood flow properties through some defective bileaflet mechanical heart valves, Technical Journal of Engineering and Applied Sciences, 3(10), pp. 898-903

20. Takabi, B., 2016, Thermomechanical transient analysis of a thick-hollow FGM cylinder, Engineering Solid Mechanics, 4, pp. 25-32.

21. Albadra, J., Tayala, S., Alasadib, M., 2013, Heat transfer through heat exchanger using Al2O3 nanofluid at different concentrations, Case Studies in Thermal Engineering, 1(1), pp. 38-44.

22. Gheitaghy, A.M., Takabi, B., Alizadeh, M., 2014, Modeling of laser irradiation in the cornea tissue based on hyperbolic and parabolic heat equation with electrical simulation method, International Journal of Modern Physics C, 25(9), doi: http://dx.doi.org/10.1142/S0129183114500399

23. Bejan, A., Kraus, A.D., 2003, Heat Transfer Handbook, Wiley-Interscience.

24. Das, S.K., Choi, S.U.S., Yu, W., Pradeep, T., 2008, Nanofluid: Science and technology, John Wiley and Sons. 